\title{
Conceptualizing Individual and Household Disaster Preparedness: The Perspective from Cameroon
}

\author{
Emmanuel Nzengung Nojang ${ }^{1} \cdot J_{\text {Jessica Jensen }}^{2}$
}

Published online: 5 March 2020

(C) The Author(s) 2020

\begin{abstract}
This research explored the basic issue of what preparedness means and entails to people in Fako Division, Cameroon-a place threated by many hazards and that has experienced many disasters. Findings from the analysis of the 33 interviews conducted in this study indicate that preparedness is a dynamic state of readiness that is dependent on context, a social process, and a process of completing activities to save lives and minimize the effects of disasters. In addition, the research determined that Cameroonians view a wholly prepared person as someone who would: (1) have knowledge about hazards and what to do about them; (2) engage others, including their families and neighbors, in discussions about activities related to hazards; and (3) participate in activities to minimize loss from hazards, sustain themselves in the face of hazards, and flee from hazards. The findings from the interview data synchronize to a large extent with what is implied, but not clearly stated, in the existing research literature. The article addresses this synchrony, posits a definition of preparedness, and identifies the theoretical components of preparedness.
\end{abstract}

Keywords Disaster theory - Emergency management · Hazards preparedness - Individuals and households $\cdot$ Risk management

Emmanuel Nzengung Nojang

emmanuel.nojang@gmail.com

1 Department of Political Science and Public Affairs/Homeland Security and Emergency Management Program (PSPA/ HSEM), Savannah State University, Savannah, GA 31404, USA

2 Department of Emergency Management, North Dakota State University, Fargo, ND 58105, USA

\section{Introduction}

Cameroon is located on the west coast of central Africa. This article reports the results of an individual and household preparedness (IHP) study that focused on Fako Division in the Southwest Region of Cameroon. Of all divisions, Fako is in the closest proximity to most of the nation's hazards and has had the most recent hazard events. Significant risks in Fako Division include volcanic eruptions, landslides, major storms, human immunodeficiency virus/acquired immune deficiency syndrome (HIV/AIDS), and malaria.

Residents within communities across Cameroon are also vulnerable to hazards and associated events (Bang and Few 2012; Tongwa et al. 2012; Kometa 2012; Bang 2013; Ndille and Belle 2014). Cameroon has a diverse array of vulnerabilities that can be classified as social-economic, physical, environmental (Bang 2013, 2014), infrastructural, and political (Balgah et al. 2015). Yet, only a mediocre effort has been, and is being, made to address these vulnerabilities at the national level (Njome et al. 2010; Tongwa et al. 2012; Bang 2014; Ndille and Belle 2014).

Many authors have argued that the potential impacts of hazards and associated events on people and property could be lessened with adequate IHP, and have maintained that IHP is linked to the ability of communities to contend with these events effectively (Kapucu 2008; Kusenbach et al. 2010; Kano et al. 2011; Bourque et al. 2012). This article reports the results of a study that explores how Cameroonians conceptualize IHP across hazards and discusses the extent to which the study results align with a conceptual model of preparedness induced from the disaster literature. 


\section{Literature Review}

Individual and household preparedness has been studied intensively for the last two decades, both within the United States and in other countries (Andrews 2001; Nguyen et al. 2006; Spittal et al. 2008; Basolo et al. 2009; Kim and Kang 2010; Ronan et al. 2012). The body of work generally concludes that some individuals and households (IHs) are somewhat prepared but most are generally not. Yet there are significant issues in the IHP literature that undercut the validity of these findings. These qualifications of the conventional wisdom about the value of disaster preparedness are discussed in the following three subsections.

\subsection{Individual and Household Preparedness Literature Critique}

Definitions of concepts (and related dimensions if appropriate) are foundational to science and constitute the building blocks of theory. They provide structure to facilitate cumulative inquiry and provide a basis upon which to insure science is self-correcting (Maxim 1999; Babbie 2015, 2016). The vast majority of the literature on IHP fails to present a clear theoretically-grounded definition of the concept, that is determine what IHP means. The literature has not yet articulated what a wholly prepared IH would look like, that is, what are the dimensions of the concept that together make an IH prepared and which among them are most important to IH disaster outcomes. These issues are rampant in the United States-focused literature (Andrews 2001; Basolo et al. 2009; Bourque et al. 2012), and also exist in the international literature on the topic of IHP (Boon 2013; Doocy et al. 2013; Gowan et al. 2014).

A description of IHP is not the same as a theoreticallygrounded definition. When offered, descriptions typically depict IHP as the process of getting ready for or completing activities related to hazard events. Yet the scholars who operationalize IHP tend to go on to measure it as a state without mention of the consequences of such a theoretical disconnect (Basolo et al. 2009; Bourque et al. 2012).

In the rare cases where actual definitions are offered, they are similar-IHP refers to IHs doing or having things both within the US literature (Edwards 1993; Basolo et al. 2009; Kim and Kang 2010) and that external to the United States. (Kirschenbaum 2002; Benson et al. 2007; Buckle 2012). Preparedness theory is consistently absent in these cases-no presentation of what a wholly prepared IH would consist of is offered concurrent with these definitions. And there is no consensus on any of the definitions that are reflected in the literature-no single one has been frequently cited. This issue is not limited to Western- centric literature; it also exists in the non-Western literature on IHP.

Adding to these issues, scholars tend to operationalize IHP in ways that are generally similar but different enough to have implications for interpretation of findings across the body of work and, subsequently, for theory development. The most common way to operationalize IHP is as a simplistic inventory of activities or supplies. These inventories are often derived from government preparedness literature in both US-focused and international research by, for example, the US Federal Emergency Management Agency (FEMA), the Red Cross, and various United Nations inventories (Kelley 2011; Perman et al. 2011; Heagele 2016).

There are multiple challenges with operationalization of IHP as an inventory. Individuals and households are asked during data collection which of these inventory activities they have undertaken and which of the identified supplies the IH has on hand. They are typically asked to reply with a yes or no for each item on the inventory. Examples of common inventory items include whether the IH has: a plan, batteries, wrench, first aid kit, food, and water. Yet, the wording of these items varies significantly from study to study. There is a difference between asking whether an IH has food, food for three days, food to feed everyone in the household for three days, nonperishable food, and so on (for example, Paton (2003) versus Spittal et al. (2008), versus Baker and Cormier (2013).

The listed items most commonly appear associated with a period widely known as response, or when IHs take immediate action to save their own lives and/or preserve their own property as opposed to recovery, when IHs attempt to address what has been impacted by a hazard event. Is not a wholly ready IH ready for recovery as well as response? If so, the current IHP inventory approach does not adequately account for IH readiness for recovery. Regardless, no basic argument is offered suggesting that a fully completed inventory makes an IH wholly ready for response anyway. Adding to the problems with IHP operationalization are the fact that inventory items are often developed in culturally-specific, hazard-specific, and/or place-specific ways. This reality is only problematic in the absence of a theoretical definition of IHP and articulation of its dimensions in which to ground findings.

IHP scholars have been interested in potential influences on variation of IH inventory items. Their focus has often been directed at explaining variations in the total number of items IHs had on hand with each listed item treated equally-all yes responses equal 1 rendering having a wrench as equal to the value of having an evacuation plan in terms of IHP. Alternatively, some scholars explore what might explain why a given IH has undertaken each individual activity and acquired each individual supply. It is 
here, in scholars' desire to anticipate or generate explanation for variation in inventory items that theory is leveraged. Scholars have utilized person-relative-to-event theory, social cognitive model, protection mitigation theory, vested interest theory, theory of planned behavior, and other theories to explore this interest and have leveraged a diverse array of independent variables. But inventory items - independent variable relationships-are inconsistent. A likely reason for this instability stems from inconsistent operationalization of IHP — a problem that stems from a lack of IHP theory.

\subsection{The Holistic Individual Preparedness Model}

These critiques are presented to students in courses within the emergency management graduate program at North Dakota State University (Jensen 2014). The definition students are taught reconciles some of these issues. Students are taught that IHP is "a state of readiness for effective response and holistic recovery to hazard events determined both by their status relative to 6 dimensions at any given time and the community context surrounding them" (Jensen 2014). The six theoretical dimensions to which the definition refers include knowledge, subsistence, loss minimization, mental and physical adaptive capacity, social integration, and information source integration (Fig. 1).

Jensen (2014) maintains there is value in these dimensions because they are empirically grounded and together represent a more holistic conceptualization of what comprises IHP. The dimensions may also be valuable because they facilitate research across time, space, and culture, and because, while each may be variously operationalized, findings can be tied back to theory (Jensen 2014).

The first three dimensions were deduced from the extant IHP literature as the theoretical interest that underlies inclusion of related items in IHP inventories.

- Knowledge Analysis of inventory items suggests that scholars are fundamentally interested in individual and household ( $\mathrm{IH})$ knowledge of hazard risks and suitable behaviors in response. The consistent inclusion of an inventory item inquiring whether an IH has some form of plan seems to reflect an interest in whether the IH know what they will do in the face of a hazard event (Phillips et al. 2005; Nguyen et al. 2006; Redlener and Berman 2006; Eisenman et al. 2009). Various other seemingly knowledge-related items are often included such as if the IH has learned how to turn off utilities (Farley et al. 1993; Heller et al. 2005; Bourque et al. 2012) or if they attended a class workshop on
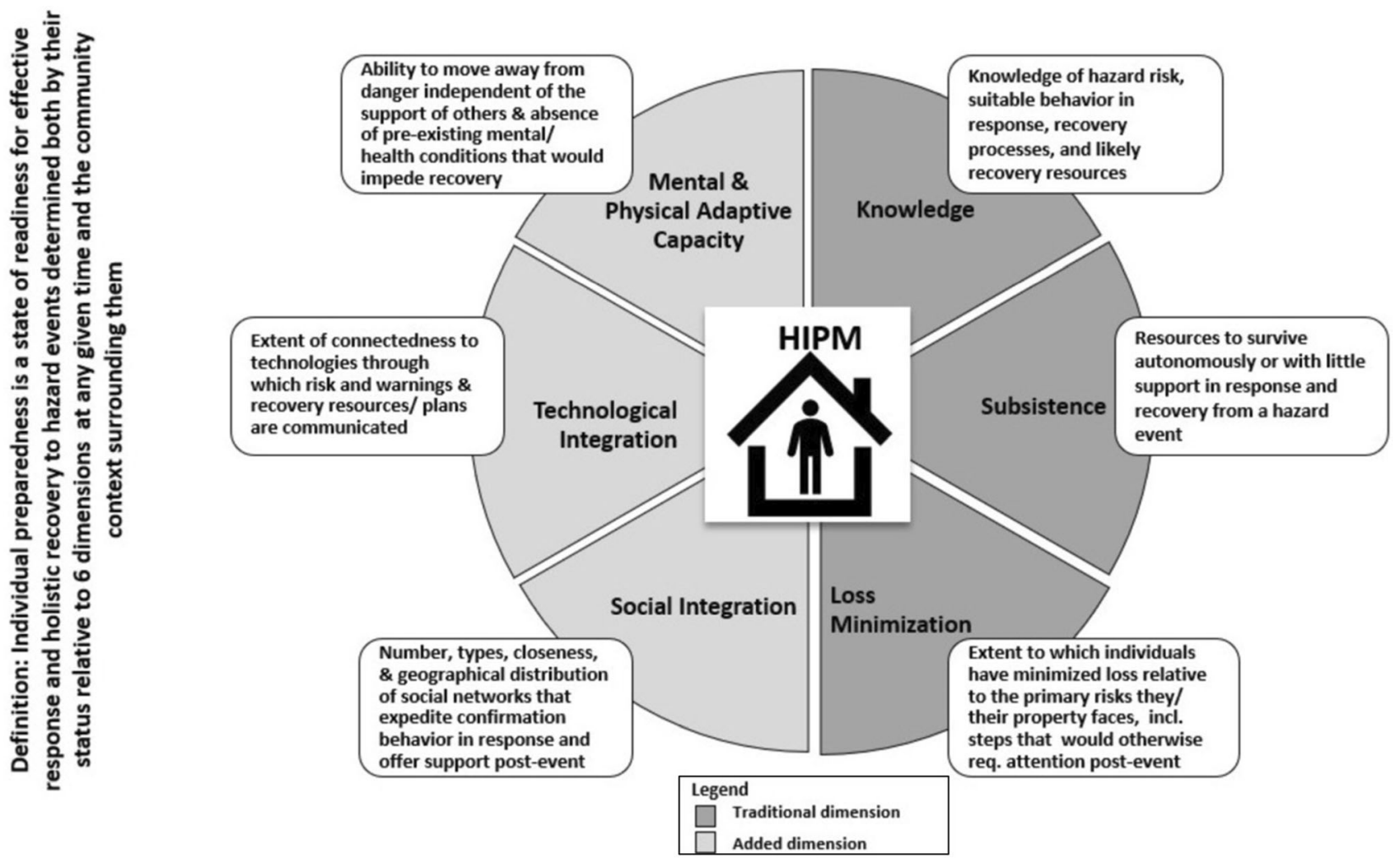

Fig. 1 Holistic Individual Preparedness Model (HIPM). Source Jensen (2014) 
preparedness (Andrews 2001; Phillips et al. 2005). Knowledge is rarely assessed in the context of recovery. For example, knowledge of contact information and account number for creditors and insurers, workpolicy-related compensation after disasters, jurisdictional recovery plans and priorities seldom appear in plans. It would appear that recovery knowledge would facilitate better recovery outcomes; that is, those who have those data before disaster would be more ready yet scholars have not included such items in their inventories when assessing IHP.

- Subsistence Inventories consistently ask if IHs have food (Dooley et al. 1992; Horney et al. 2008; Eisenman et al. 2009), cash on hand (Siegel et al. 2003; Eisenman et al. 2009), an emergency kit (Andrews 2001; Phillips et al. 2005), a flashlight (Edwards 1993; Nguyen et al. 2006; Eisenman et al. 2009), radio (Andrews 2001; Heller et al. 2005; Spittal et al. 2008), and countless other supplies that all seem somehow related to an underlying interest in whether IHs have what they need to survive in the immediate aftermath of an event, prior to a hazard event occurring. Scholars' inclusion of inventory items such as insurance (Edwards 1993; Farley et al. 1993; Andrews 2001; Heller et al. 2005; Nguyen et al. 2006) and important documents (Eisenman et al. 2009; Bourque et al. 2012) suggests that at least some scholars are sensitive to the IH need to be ready for recovery, not just response.

- Loss Minimization Still other inventory items appear focused on assessing the extent to which individuals have minimized loss relative to the primary risks they and their property face, including whether they have taken steps that would otherwise require attention postevent. The specific item(s) that seem to reflect this dimension vary, but examples include securing furniture (Farley et al. 1993; Andrews 2001; Heller et al. 2005), securing moving objects (Spittal et al. 2008), adding structural support to the home (Edwards 1993; Eisenman et al. 2009), putting latches on cupboards and cabinets (Nguyen et al. 2006; Spittal et al. 2008), and getting sandbags (Siegel et al. 2003).

The remaining three dimensions stem from integration and synthesis of the literature on what explains IH outcomes in response and recovery.

- Social Integration The response literature implies that IH social integration is related to human behavior in response. Individuals and households must confirm warnings, through a social process, prior to determining how they will, in turn, respond (Mileti and Sorensen 1990; Lindell and Perry 2012). It stands to reason that those who are more social connected will confirm and act faster than those who are not. Social integration appears to be just as important in recovery since IHs' most preferred and accessed source of financial, in kind, and mental health support comes from an individual's social networks (Kaniasty and Norris 1995; Bonanno et al. 2007; Forgette et al. 2009; Onstad et al. 2012). Thus, it appears that the more social links one has (of diverse types and in varying locations), the more ready one is for both response and recovery even while integration is not assessed as a component of IHP historically.

- Information Source Integration Access to information is critical to $\mathrm{IH}$ outcomes in both response and recovery. Having access to information through multiple platforms (for example radio, television, social media, and formal warning technologies) increases the likelihood that IHs will receive critical response-related information, for example, warning messages (Kirschenbaum 1992; Tierney et al. 2001; National Research Council 2006; Lindell and Perry 2012; Lindell et al. 2013). Individuals and households need knowledge to address recovery concerns and knowledge is contingent on access to information (at least in significant part). They often require information about reentry (Lin et al. 2014), post-disaster assistance sources and how to access them (Longstaff 2005; Pleissis et al. 2015; Rivera 2017; Chandrasekhar et al. 2018), how to complete recovery tasks (Opdyke et al. 2018), and opportunities to engage in wider community recovery planning efforts (Denters and Klok 2010). It appears that the more connected IHs are to sources of information central to response and recovery pre-disaster, the more ready they are to access needed information and act in keeping with it; yet, scholars have not historically assessed information source integration when researching IHP.

- Mental and Physical Adaptive Capacity Research consistently has shown that mentally and physically healthy people adapt better in both response and recovery. Individuals with preexisting mental health conditions, preexisting or chronic health condition, and disabilities are injured and die more often than individuals without these characteristics; those without challenges due to mental or physical health impediments are able to respond most quickly and appropriately (National Research Council 2006; Uscher-Pines 2009; Fujii 2012; Phibbs et al. 2015). Additionally, individuals with preexisting mental health or physical health conditions also suffer more in the recovery period than those without; and, those without mental and physical health challenges navigate the recovery process most quickly and fully (Norris et al. 2002; Bonanno et al. 2007; Kölves et al. 2013; Stough et al. 2016). These findings appear to hold true when 
controlling for other factors like age, socioeconomic status, gender, race and ethnicity, and so on even while more, and more sophisticated, generalizable research is needed. Undoubtedly, IHs have limited direct control over their mental and physical wellness. Nevertheless, understanding their health is an indicator of how ready they are for hazard events and should be included as part of how we assess IHP.

\subsection{Methodological Issues}

The absence of a clearly articulated definition of the preparedness concept and a connection between preparedness activities and response and recovery is not only responsible for lack of an articulation of why the recommended preparedness activities are important to the state of being prepared, but also for the way the concept has been measured and operationalized in the literature. In addition, the use of varying theoretical variables and operationalization of these variables, makes the generalization of the findings from these studies problematic (Lindell and Perry 2000; Tierney et al. 2001; Levac et al. 2012; Bourque et al. 2012; Donahue et al. 2014).

There also are issues with the data collection methodology reflected in the literature (Lindell and Perry 2000; Bourque et al. 2012). While the social sciences offer a wide variety of rich data collection methodology, such as participant observation, in-depth interviews, and so on (Rubin and Rubin 2012), the vast majority of IHP literature is based on self-reported surveys (Dooley et al. 1992; Andrews 2001; Nguyen et al. 2006; Basolo et al. 2009; Eisenman et al. 2009; Bourque et al. 2012). Self-reported surveys are a valuable way of collecting data (Dillman et al. 2014). Yet independent and dependent variables in quantitative surveys ought to be, ideally, designed vis à vis theory (Babbie 2015, 2016). While there have been a few notable exceptions (Baker 2013, 2014), the IHP literature appears to reflect a move directly into quantitative testing without working from a theoretically grounded definition of IHP - the very dependent variable they operationalized and studied. The Jensen (2014) definition and dimensions of preparedness are theoretically grounded and seemingly resolve some of the existing problems in the IHP literature. But this definition is novel still, unpublished and untested. Rather than quantitatively testing it at this stage, it is most appropriate to undertake qualitative research to further tease out the meaning of IHP; and, at a later stage of analysis, to compare what is found to this new conceptual model.

\section{Methods}

This article reports the results related to a qualitative study of how Fako Division residents in Cameroon's Southwest Region conceptualize IHP. Qualitative methods can be employed to "unpack issues, to see what they are about or what lies inside, and to explore how they are understood by those connected with them" (Ritchie and Lewis 2003, p. 27).

\subsection{Participants and Sampling}

To gather needed relevant data, this study initially employed a purposive sampling technique (Patton 2002). Initially, 91 local chiefs in Fako Division of Cameroon's Southwest Region were purposively sampled for this study (Fig. 2). In Cameroon, local chiefs and subchiefs are traditional leaders within their communities, and these individuals are perceived to be responsible for protecting and ensuring the socioeconomic and cultural well-being of their constituents (Jua 1995; Rouveroy van Nieuwaal and van Dijk 1999). Additionally, the local chiefs are citizens who live in Fako Division and are exposed to the hazards that threaten the area. They may have even experienced one or more disasters. For these reasons, the chiefs are positioned to speak, not only about how they conceptualize preparedness personally but also about their perspective on the meaning of the concept more widely in their community.

The researchers also employed the snowball sampling technique (Bachman and Schutt 2013; Babbie 2016) by asking chiefs who had already participated in the interviews and understood the purpose of this study to facilitate the recruitment of other chiefs.

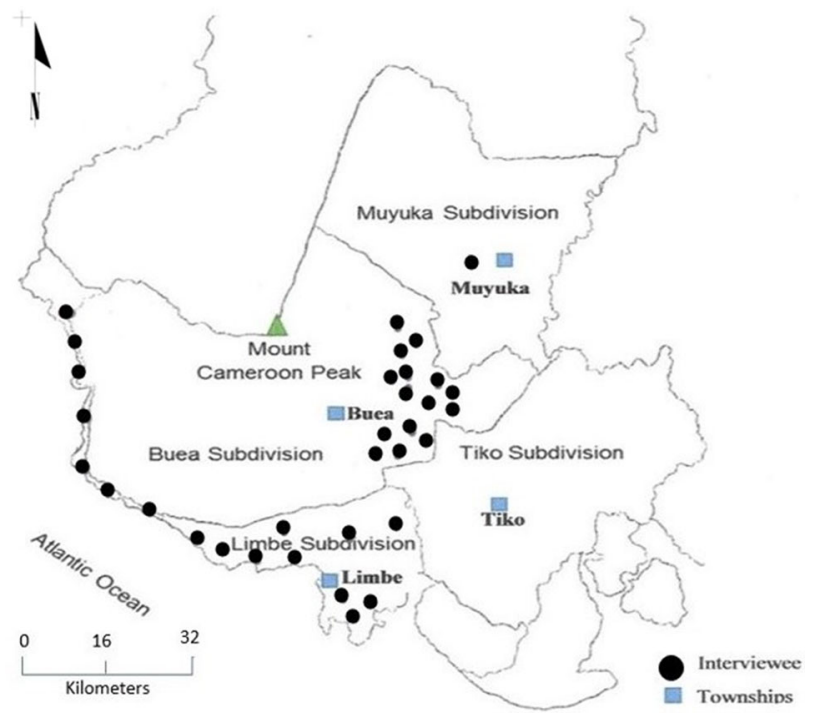

Fig. 2 Map of Fako Division, Cameroon, highlighting interview locations and major townships 


\subsection{Data Collection}

In accordance with the Responsive Interview Model (Rubin and Rubin 2012), face-to-face, in-depth, semistructured interviews were used to collect the data. The researchers conducted pilot phone interviews with three selected key informants who all reside in Fako Division of Cameroon's Southwest Region to determine the practicality of and extent to which the interview questions generated needed data. The pilot interviews led to minor changes to the interview guide. Ultimately, the main interview questions included: (1) Let's get started by you telling me about hazards in your area; (2) Tell me about some of the disasters that have resulted from these hazards; (3) What does preparedness mean for you?; (4) Is there anything else about hazards, disasters, or preparedness that you want to share with me at this time? Probes and follow-up questions were leveraged to complement these main questions (Rubin and Rubin 2012). Data were collected January-March 2015. Data collection continued until theoretical saturation was reached, or the point, according to Strauss and Corbin (1998, p. 188), when "no new or relevant data seem to emerge regarding a category; the category development is dense, insofar as all the paradigm elements are accounted for, along with variation and process; and the relationships between categories are well established and validated."

\subsection{Data Analysis}

After conducting the 33rd interview and reviewing notes after each interview was completed, the researchers concluded that the 28th interview rendered as much useful information as the 33rd interview and that no new themes emerged between interviews 28 and 33. Thus, the researchers concluded that theoretical saturation had been reached and ended the interview process.

The interviews were recorded using a digital recorder and transcribed. The data were analyzed using the two phases of Rubin and Rubin's (2012) Responsive Interview Model. During the first phase, a "transcript that contains a full and accurate word-for-word written rendition of the questions and answers" was prepared (Rubin and Rubin 2012, p. 190). After transcribing, a summary of the content of each interview was written, including the main points made that address the research question, names or pseudonyms of the interviewees, time and location of the interview, and the reason why the interviewee was included in the study (Rubin and Rubin 2012, p. 192). During transcription, memos containing researcher thoughts and references to potential emerging themes and concepts were written (Rubin and Rubin 2012).

The first stage of analysis revealed that a number of activities discussed by the chiefs could be generally classified under certain specific theoretical labels. Thus, the interviews were coded in a systemic manner with codes, such as actions to minimize loss, knowledge, integration, finance, mobility, and subsistence, placed next to each data segment representing the concept of theme. The coded data were then analyzed for broader implications (Rubin and Rubin 2012). Using diagraming charts and figures to integrate both of these phases in the data analysis process drew out possible relationships between categories and provided an in-depth understanding of the relationship of the data to the research question for this study. The coded data were analyzed looking for sets of related themes and concepts that answer the research question while providing detailed descriptions and explanations of the findings. This process of combining themes that highlighted causes and consequences may lead to the generation of a theory (Rubin and Rubin 2012). Yet the researchers did not develop a theory; instead, they analyzed the results against the Jensen (2014) conceptual model of preparedness.

\subsection{Limitations}

The sample size was small and nonrandom; thus, the results were not generalizable to Cameroonians in Fako Division. Additionally, the focus on a single nation excluded the perspective of additional nations in other regions of the world. The data collected could also reflect the social-desirability bias. Given the fact that the chief is a leader of his community, respondents may, due to their community affiliations, have responded in a manner that they believed would make them or their community look good. Finally, all the participants in this study were male. Although the researchers did not intend to select only male participants, in Fako Division chiefs are generally male. In Cameroon, some females have positions of authority and women, in general, are an integral part of the day-to-day operations of households. The fact that the sample did not include women means that the results are not generalizable to Cameroonians in general in Fako Division. As leaders within their communities, however, the chiefs represented their constituents and discussed the concept of preparedness within the experiences of both male and female citizens.

\section{Results}

Over $75 \%$ of the participants $(\mathrm{N}=25)$ did not offer a direct answer or could not clearly articulate what it meant for IHs to be prepared for a disaster. Interviewing participants in Cameroon's Fako Division revealed that there was no singular definition for the concept among these chiefs. Rather, there are many themes that, together, represent how 
the participants conceptualize IHP. The synthesis of the data collected for this study revealed themes that transcend the hazards common to Fako Division. For this reason, the quotations are evidence of the themes and not the hazards. The following major themes were related to the concept: knowing things, social and technological integration, and taking actions emerged during the data analysis. These themes were classified as major ones because they were identified either directly or indirectly in discussions with over $70 \%$ of the study's participants $(\mathrm{N}=24)$. The reference to a percentage of participants is merely to indicate the proportionality of participants who discussed a specific theme. The data analysis also revealed some minor themes, including subsistence and mobility. Further analysis also revealed that context too is an important aspect of IHP for these participants.

\subsection{Knowing Things}

Participants most frequently conceptualized preparedness as "knowing things" in two ways: (1) awareness; and (2) experience. Most participants interviewed for this study indicated that awareness about hazards was an important element of knowledge. Without being prompted, the participants noted that being aware of the risks associated with their areas enhanced their hazard-related knowledge. This awareness was sometimes based on the identification of some areas as risky zones by the national administration. As one participant stated, "Some areas have been identified as risky zones, and if you are going to construct there or do farming there, it is at your own risk." In addition, the participants also discussed awareness in relation to the frequency or recurrence of specific hazard events: As far as flooding is concerned, people are aware that there are many parts of Limbe that have been flooded from time to time. Because the people know that this occurs regularly, they have always taken measures to make sure that flood does not cause too much destruction to their property.

Indeed, participants noted that much of their readiness for hazard events is dependent on their knowledge. It seems that their understanding of these hazards comes, in large part, from living in these communities.

Experience is the second facet of the knowledge dimension that was prevalent in the interviews. Participants indicated that their hazard experiences-either personal or vicarious-were the best teacher. However, they also suggested that because the extent to which an individual or his/her social network has experienced a specific hazard varies, so too does preparedness. One participant explained:

I think that those that have experienced it are better prepared because they have experienced it. The other people that don't know and have never experienced it will be doubting. But if they have experienced such an issue, at least people in that area would know what to do.

Within this discussion of knowledge, the participants explained that awareness of your area and experiencepersonal or vivacious-was foundational to IH hazardrelated knowledge.

It seems that while knowledge is relevant to IHP, knowing how to use that hazard-related knowledge to reduce or minimize the effects of hazards is also fundamental to preparedness and that both are cultivated through a social process. The process may unfold merely by living in an area, experiencing hazard events, and watching others do the same and/or through actively engaging with others who share their own experience-based knowledge to the benefit of younger people and new comers. For example, an experienced person might advise: don't build your house there; leave the tree; do not build with bricks, rather build with wood; it floods every year around this period; you better put a gutter around your house; you are in a risky zone; the government is not going to come here; somebody once built a house there, so the water is going to come back. In Cameroon, there are many sources of this knowledge, both social and technological.

\subsection{Taking Actions to Minimize Loss}

Across the interviews, participants predominantly conceptualized IHP in terms of taking actions to minimize loss from hazard events. Some participants conceptualized IHP as a continuous process of taking action. Other participants explained the concept as taking steps to get to a state of readiness. Whether a continuous process or a state, to these participants IHP fundamentally meant taking real, deliberate action.

Most of the participants explained preparedness as a continuous process. For these participants, preparedness meant that people continuously engage in a variety of hazard-related actives that would enable them to minimize the impacts and to respond to and recover from hazard events. Without being prompted, participants explained that there is no point in time when people can say that they have taken enough actions to deal with the risk and threats in their areas, and as such, they are done.

Other participants expressed the opinion that people take action to get to a state of readiness. These participants indicated that people can complete certain hazard-related action to be ready to respond to and recover from hazard events. These actions may be to deal with a specific risk or threat, or hazards generally. Participants repeatedly suggested that preparedness means taking hands on actions to 
deal with prevalent hazards based on their knowledge of those hazards.

The way people are building the house is too low; for example, if you look during the rainy season, we have low tide; you can raise your house. When building your house, maybe you can put a staircase inside your house to move things up, and that is another way people can prepare. So, the way they build their houses, they can use bricks to block their house so that, when water comes, water cannot get inside your house.

Generally, participants suggested that people have knowledge about what needs to be done to prevent the effects of hazards. But they repeatedly indicated that they can only take those actions that can be accomplished personally or with their knowledge of the hazards and not those actions that require significant financial investment or technical expertise. While flooding actions involved sandbagging, suspending things, or moving possessions to a higher level for some, the threat of earthquake tremor actions involved fastening items to walls or floors. Seaside community participants talked about taking actions such as making a ditch around their houses. In communities where there were landslides, participants talked about replanting trees and preventing people from building in those areas. And across Fako Division participants often described actions using mosquito nets, washing hands, and cooking with clean water and hands to lessen the risk of disease. Actions to minimize loss, like these, were undertaken frequently by Fako Division residents and households because social integration within the Division was strong, and, hence, knowledge of what to do was widespread.

\subsection{Integration}

Participants also conceptualized IHP as integration, meaning that people within their jurisdictions are socially connected and information-source connected to communicate and to receive hazard-related information. Repeatedly these participants indicated that having relatives and friends on whom they can rely prior to, during, and after a hazard event provided them with the necessary support to deal with hazard events. For example, chiefs frequently referred to community members staying with friends, relatives, and neighbors during floods or volcanic eruptions.

The participants also explained integration as people being socially connected to other community social organizations. Repeatedly, participants spoke of receiving assistance from churches and other social groups within their communities. These interactions, established prior to a hazard event, enabled people to access these organizations for assistance in response to and recovery from the hazards common to their communities. In fact, without this integration with kin, social organizations, and the community at large, people's hazard-related experiences and awareness would neither be shared nor gained.

Social integration was by far the strongest component of IHP in Fako Division Cameroon. Its presence in Cameroonian communities facilitated information source integration and knowledge among IHs. This aspect of IHP was strong in part because it is something that the people can do with minimal cost, effort, or technology. This social integration is also, perhaps, facilitated by the Cameroonian culture where the concept of a nuclear family is almost nonexistent. A nuclear family may be understood to include a couple and their immediate, dependent children. In Fako Division, families are a complex network of relatives and extended relations, including neighbors and friends, all interacting at a very close and personal social level. In this context, social integration facilitates the social processes that acquire and transfer hazard-related knowledge.

In addition to the social process, participants also explained preparedness as people being integrated in other ways so that they can receive information like warnings and other risk communication. As one participant said, "That is why we have the radio. We have a community radio here, and we have the official radio station, Cameroon Radio and Television Company (CRTV), to inform us about dangers and what to do." Participants explained that IHs were technologically integrated with their communities through a number of modern communications such as radios, televisions, and earthquake-tremor monitoring devices. All the participants in this study indicated that they have a town crier too; that is, a person who walks around the village ringing a bell and making general announcements and transmitting warnings and other hazard-related information. Location within hearing range of the crier is very important. In addition to a town crier, participants also indicated that they make use of some traditional instruments, like drums and horns, to transmit information in emergency situations where the use of a town crier may not alone be adequate. As one participant explained, "Most people are farmers, and while they are working on their farms, they may not be able to hear the town crier."

Information-source integration was another strong component of IHP in Cameroon. The strength of this dimension stems in large part from social integration in Cameroonian communities. The strength of this dimension is also supported by the role of low cost and easy sources leveraged to communicate hazard information. 


\subsection{Subsistence}

A minor theme of subsistence emerged in data analysis. When described in the context of IHP, participants expressed subsistence as stockpiling a combination of household supplies, such as food and fuel, to cook food to survive at home for a short period of time during a hazard event.

Say, in the villages in August during the peak of the rainy season, people know what to do. The state of preparedness for that period is to amass food, firewood and keep in the houses. So that when that bad period comes, they don't go out, but they have food to eat.

Study participants spoke about subsistence as important to IHP. They suggested that the items that they collect, such as food, are simple things that they can produce by themselves given the fact that most of them engage in sustenance farming. The participants also indicated that other items, such as firewood, are things that they collect by themselves. Repeatedly, participants indicated that the things that they do in this category are things that they can do by themselves.

\subsection{Mobility}

The participants in this study indicated that IHP means mobility. Among these participants, mobility meant having access to roads, and people being physically fit to run. Within this context, these participants were saying that mobility is an integral element of their ability to deal with imminent danger. They indicated that mobility means people are physically fit to engage in activities, such as running or trekking from imminent hazards.

Yes, it has a lot if you have old people in your community and there is a problem, and they say people should leave; those old people cannot. The young people can help carry them [...] They can also facilitate their movement by putting them in vehicles like if there is a disaster where people have to evacuate.

Still other participants conceptualized mobility as having the financial capability to afford transportation, such as a car, taxi, or bus, to evacuate one's family. As one participant explained:

I can better evacuate my family if it comes. I will be prepared so that I can evacuate my family from here and go to any destination far from it. But when I am financially handicapped I cannot, I can only trek.
Regardless of whether roads were available or if people were physically fit or had the financial capability to evacuate, the common denominator was that mobility is fundamental to their ability to deal with hazards and associated events. For this reason, these participants conceptualized IHP as such.

\subsection{Finance}

Another aspect of IHP is finance. The data analysis indicated that IHP was conceptualized within the context of these themes because, to these participants, they can afford to do these things:

If you have the means to prevent it, you should. Those who do not have money, what I can say is that all of us are praying that bad things should not come because all hands are not the same. Some people are poor; some are rich, but for the poor ones, when this disaster comes, they cannot do anything.

The data indicated that, to participants, preparedness is more than how they spoke about doing it-the concept also included things they could not do or buy due to the state of family finances. In fact, the initially minor themes actually transform into major ones when considered next to the theme of finances as part of IHP.

Because participants cannot afford a wide range of material things, they focused on what they could do by themselves in their narrative. Nonetheless the results should not be taken to mean that the participants were not aware of those key parts of preparedness.

Some people have money but neglect to do something, and when there is a water disaster, some people say that, if I had known, I would have built a better house on a different site. And some really do not have money.

In addition to taking loss-minimization actions, participants also suggested that finances would allow IHs to engage in activities that would facilitate response to hazards and associated events.

But if we do, where are the resources that we muster for that kind of thing? Villages and villagers don't have that kind of money. In my village, we try to use some money from taxation, like land taxes, to do a few things like building bridges and for some emergencies in the village and for doing any little thing that we can. That is all; it is not for things like this.

Other participants indicated that having financial resources allows IHs to engage in activities that would allow them to subsist post disaster and to purchase reconstruction supplies. 
Finances, too, would help us prepare. I would be able to buy a bag of cement. I would be able to buy food. I would be able to buy many things to keep and to store for those rainy days.

These participants suggested that, given the fact that most of the people in their community are not financially secure, their ability to know things and do them with their own hands, based on their social and information-source integration enables them to ready themselves for hazard events even if their ultimate readiness will be limited.

\subsection{Context and IHP}

During the interviews, the context in which IHs live in Cameroon was critical to their readiness and even their understanding of the preparedness concept. The majority of the participants do not know about the existence of a disaster management agency in Cameroon, although they are required by law to execute an emergency management role within their communities. Only one of these chiefs had received disaster preparedness training (and he had received his training while working in China). Furthermore, none of the participants mentioned having had a conversation with any Cameroonian emergency management professional or nongovernmental organization representative at any point. The absence of a national discourse about preparedness seems relevant to people's understanding of the concept and actual readiness.

The lack of investment in readiness in the country as a whole is relevant to any discussion of IHP too. Cameroon is a developing country located on the west-central coast of Africa. Capacity and responsibility for capacity building are viewed within Cameroon as shared with entities within the country's borders and beyond. International and interregional organizations, such as the IMF, the United Nations, and the World Bank, are generally involved in the country's day-to-day activities and support development of transportation, agriculture, economic diversification, public health concerns, banking, and other socioeconomic aspects. Capacity is viewed as shared because there is insufficient capacity within Cameroon to address these issues alone. And preparedness is not a primary focus for those entities supporting Cameroon day-to-day in light of these other seemingly more urgent development issues. Thus, IHs in Cameroon are surrounded by weak institutions and infrastructure and live in a country unprepared for hazardous events.

Participants did not trust that the government, or outside entities, would show up at all if there was a hazard event, much less when or with what they might appear. IHs are the only bedrock elements that build hazard knowledge in Cameroon, take action to minimize hazard impacts, promote integration socially and technologically within their communities, and remain subsistent and mobile. Even where IHs are able to address IHP fully, they live in a dangerous context they have no control over and their efforts will only ready them to a point.

\section{Discussion}

Generally, disaster scholars have used the IHP concept without clearly articulating what the concept means or what a holistically prepared individual or household comprises. This article began with a critique of IHP research and an introduction of an alternative way of conceptualizing IHP - as a combination of six dimensions oriented to both response and recovery. But to this point IHP has not been a theoretically grounded concept, and the Jensen (2014) model has remained untested. It made the most sense to the researchers to do what the extant research appears not to have done-qualitative work to tease out what the concept of IHP might mean and entail and only afterward compare it to the Jensen (2014) model.

This qualitative study explored the concept of IHP in a setting far from where most such research has been conducted-Cameroon. Like many preparedness scholars, participants could not offer a clear articulation of what IHP means. It became apparent, however, through data analysis that the following themes-integration with regard to both social and information source, gaining knowledge, and taking action (that is, loss minimization, prevention, subsistence, mobility) were implied by what the participants said, with each theme representing a piece of what might represent a whole- $\mathrm{a}$ definition of IH preparedness (Fig. 3).

The picture of IHP revealed in data analysis maps onto the Holistic Individual Preparedness Model (HIPM) introduced by Jensen (2014) even while there are key differences.

Knowledge, loss minimization, social integration, and technological integration came through as key aspects of IHP in data analysis, just as they are in the HIPM. Knowledge was thought of by participants in a manner similar to how it emerged through literature review. Similarly, participants thought about social integration in synchronization with the literature review, with one exception. Cameroonian participants did not anchor these aspects of IHP, or any others, relative to recovery as much as they did response. The way participants thought of technological integration as information-source integration was very similar to how it was reflected in the HIPM; but participants also included additional information sources in their descriptions, which are foreign in the West (for example, town criers and drums) where most of the IHP 

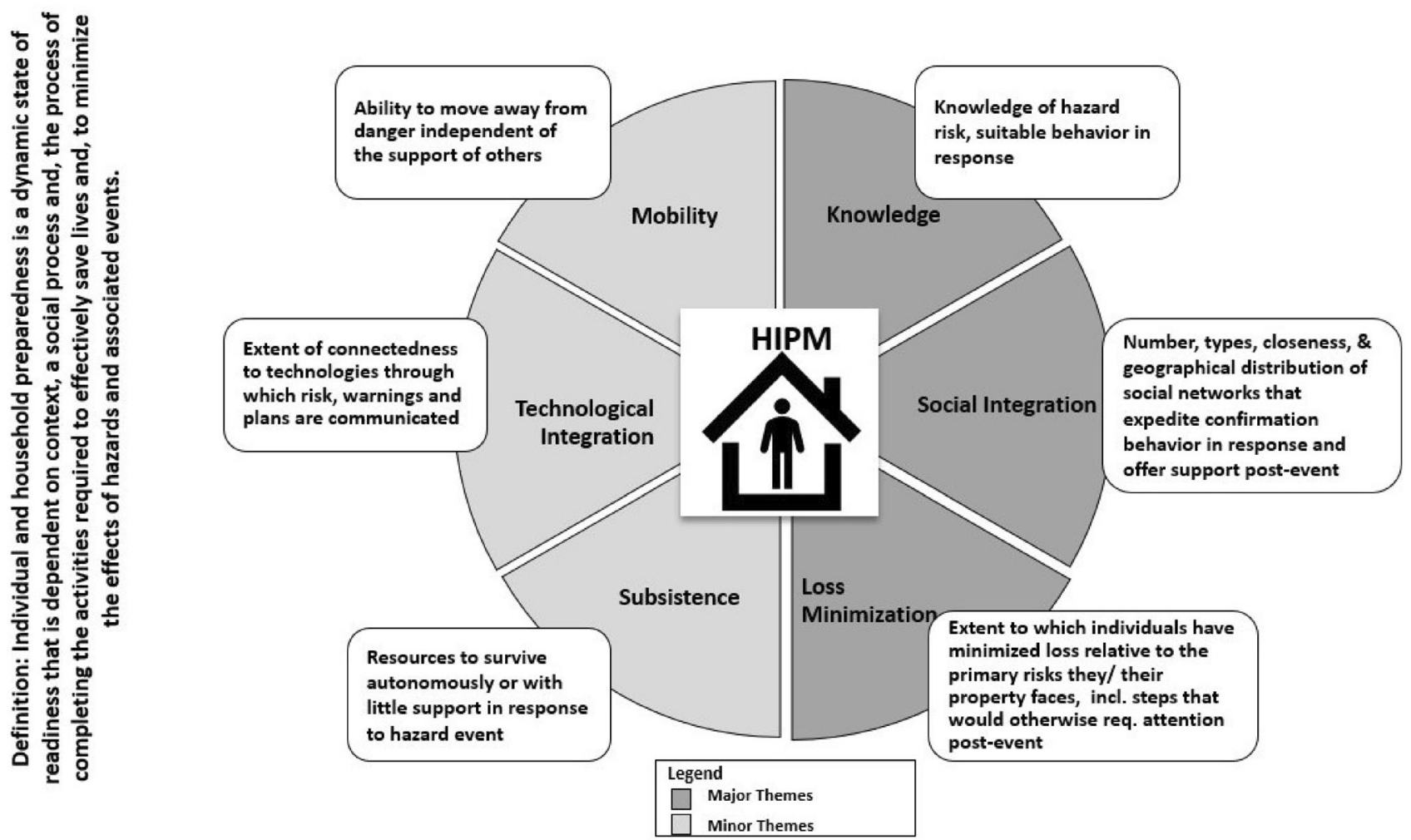

Fig. 3 Fako Division, Cameroon conceptualization of disaster preparedness in light of Holistic Individual Preparedness Model (HIPM)

research has been focused. Data analysis also revealed support for the subsistence dimension of preparedness in the HIPM. Whereas the Western-centric literature is heavily weighted towards having a variety of resources to be subsistent, in the Fako Division, when participants discussed subsistence, they primarily focused on storing food or equipment and fuel needed to prepare food. Given the fact that most people in this region are poor and make their living by farming or fishing, it was understandable that they discussed subsistence only in terms of things that they can provide for themselves as opposed to things they would have to buy. They recognize the potential value of having more resources, but cannot afford the expense.

Finances featured prominently in the data analysis. Adequate finances should actually be considered part of what it means to be subsistent, and this conception has relevance for response and recovery. The only dimension of the HIPM that was not strongly supported in participant discussions of preparedness was the mental and physical adaptive capacity dimension of preparedness. Participants recognize the importance of being physically fit to run or trek when threatened by hazard events, but that was the only aspect of this dimension that emerged in the interview data.

The similar conceptualization of IHP among Cameroonian chiefs and the Holistic Individual Preparedness Model
(HIPM) has implications for IHP theory. The HIPMgrounded in the IH preparedness, response, and recovery literature and presuming to capture how a wholly ready IHP would be structured - seems to be generally applicable in a Cameroonian context. Clearly certain dimensions would be operationalized differently in the Cameroonian context (that is, information-source integration and subsistence) based on what is appropriate in Cameroon. Certain dimensions could also be operationalized specific to hazards in one region or another within Cameroon, or, again, in any other country. Dimensions could be explored at different points in time. Because the dimensions are theoretical and supersede any specific measurements of IHP, findings across nation, hazard, and time might be summarized and better understood. The findings from this research suggest the Jensen (2014) HIPM has some initial value and ought to be further explored, as should any other theoretical, empirically grounded conceptualization that is based on evidence of what actually drives individual and household outcomes in response and recovery. Regardless of which conceptualization future scholars test, study of IHP based on theory is urgently needed. 


\section{Conclusion and Recommendation}

The concept of IHP is not new. Large sums have been invested in studying IHP, and for good reason. Disasters are increasing, as are their consequences (Mileti 1999; National Research Council 2006). Practitioners and elected officials have an interest in knowing how ready people are for hazard events. Prior to exploring what disaster preparedness entails, scholars have jumped into quantitative testing of the concept. Scholars operationalize the concept differently one to the next. And the theoretical focus of scholars is primarily on what explains variation in IHP as they measure it. This situation is problematic from a scientific and practical viewpoint.

This qualitative study of IHP supported the HIPM theoretical model. The primary implication of this support is that a universal, theoretical conceptualization of IHP may be possible. This study represents only a small step towards developing IHP theory, and there are many ways that future research may expand on this work. Future studies could explore the relevance of HIPM through qualitative and, pending those results, quantitative work. Alternate theoretical, empirically grounded conceptualizations of the preparedness concept (complete with definition and identification of dimensions) should be explored. Scholars might also examine further what $\mathrm{IH}$ readiness for response and recovery includes and insure that new findings are added into the HIPM or other models. Any future testing of the HIPM model, or any other conceptualization posited, should purposefully include multiple regions of the world and multiple hazard contexts.

Open Access This article is licensed under a Creative Commons Attribution 4.0 International License, which permits use, sharing, adaptation, distribution and reproduction in any medium or format, as long as you give appropriate credit to the original author(s) and the source, provide a link to the Creative Commons licence, and indicate if changes were made. The images or other third party material in this article are included in the article's Creative Commons licence, unless indicated otherwise in a credit line to the material. If material is not included in the article's Creative Commons licence and your intended use is not permitted by statutory regulation or exceeds the permitted use, you will need to obtain permission directly from the copyright holder. To view a copy of this licence, visit http://creativecommons. org/licenses/by/4.0/.

\section{References}

Andrews J. 2001. Safe in the 'hood: Earthquake preparedness measures in mid-city Los Angeles. Natural Hazards Review 2(1): $1-11$.

Babbie E. 2015. The practice of social science research, 14th edn. Belmont, CA: Thomson Wadsworth.

Babbie, E. 2016. The basics of social research, 7th edn. Belmont, CA: Thomson Wadsworth.
Bachman, R., and R. Schutt. 2013. The practice of research in criminology and criminal justice. Thousand Oaks, CA: Sage.

Baker, N. 2013. Role of explicit and implicit practices in the production of situated preparedness for disasters. Natural Hazards Review 15(4). https://doi.org/10.1061/(asce)nh.15276996.0000127.

Baker, N. 2014. "Everything always works": Continuity as a source of disaster preparedness problems. International Journal of Mass Emergencies and Disasters 32(3): 428-458.

Baker, L., and L. Cormier. 2013. Disaster preparedness and families of children with special needs: A geographic comparison. Journal of Community Health 38(1): 106-112.

Balgah, R.A., G. Buchenrieder, and I.N. Mbue. 2015. When nature frowns: A comprehensive impact assessment of the 2012 Babessi floods on people's livelihoods in rural Cameroon. Jàmbá: Journal of Disaster Risk Studies 7(1): Article 197.

Bang, H. 2013. Governance of disaster risk reduction in Cameroon: The need to empower local government. Jàmbá: Journal of Disaster Risk Studies 5(2): 1-10.

Bang, H. 2014. General overview of the disaster management framework in Cameroon. Disaster 38(3): 562-586.

Bang, H., and R. Few. 2012. Social risks and challenges in postdisaster resettlement: The case of Lake Nyos, Cameroon. Journal of Risk Research 15(9): 1141-1157.

Basolo, V., L.J. Steinberg, R.J. Burby, J. Levine, A.M. Cruz, and C. Huang. 2009. The effects of confidence in government and information on perceived and actual preparedness for disasters. Environment and Behavior 41(3): 338-364.

Benson, C., J. Twigg, and T. Rossetto. 2007. Tools for mainstreaming disaster risk reduction: Guidance notes for development organizations. Geneva: ProVention Consortium.

Bonanno, G., S. Galea, A. Bucciarelli, and D. Vlahov. 2007. What predicts psychological resilience after disaster? The role of demographics, resources, and life stress. Journal of Consulting and Clinical Psychology 75(5): 671-682.

Boon, H. 2013. Preparedness and vulnerability: An issue of equity in Australian disaster situations. The Australian Journal of Emergency Management 28(3): 12-16.

Bourque, L., D. Mileti, M. Kano, and M. Wood. 2012. Who prepares for terrorism? Environment and Behavior 44(3): 374-409.

Buckle, P. 2012. Preparedness, warning and evacuation. In The Routledge handbook of hazards and disaster risk reduction, ed. B. Wisner, J. Gaillard, and I. Kelman, 493-504. London: Routledge.

Chandrasekhar, D., R. Rothfeder, Y. Xiao, and D. Finn. 2018. What drives household recovery after disasters? A case study of New York City after 2012 Hurricane Sandy. Journal of Environmental Planning and Management 62(7): 1249-1268.

Denters, B., and P. Klok. 2010. Rebuilding Roombeek: Patterns of citizen participation in urban governance. Urban Affairs Review 45(5): 583-607.

Dillman, D., J. Smyth, and L. Christian. 2014. Internet, phone, mail, and mixed-mode surveys: The tailored design method. Hoboken, NJ: Wiley.

Donahue, A., C. Eckel, and R. Wilson. 2014. Ready or not? How citizens and public officials perceive risk and preparedness. American Review of Public Administration 44(4 suppl): 89S$111 \mathrm{~S}$.

Doocy, S., E. Russell, Y. Gorokhovich, and T. Kirsch. 2013. Disaster preparedness and humanitarian response in flood and landslideaffected communities in eastern Uganda. Disaster Prevention and Management 22(4): 326-339.

Dooley, D., R. Catalano, S. Misha, and S. Serxner. 1992. Earthquake preparedness: Predictors in a community survey. Journal of Applied Social Psychology 22(6): 451-470. 
Edwards, M. 1993. Social location and self-protective behavior: Implications for earthquake preparedness. International Journal of Mass Emergencies and Disasters 11(3): 293-303.

Eisenman, D., D. Glik, L. Gonzalez, R. Maranon, Q. Zhou, C.H. Tseng, and S. Asch. 2009. Improving Latino disaster preparedness using social networks. American Journal of Preventive Medicine 37(6): 512-517.

Farley, J., H.D. Barlow, M. Finkelstein, and L. Riley. 1993. Earthquake hysteria, before and after: A survey and follow-up on public response to the Browning Forecast. International Journal of Mass Emergencies and Disasters 11(3): 271-277.

Forgette, R., B. Dettrey, M. Van Boening, and D. Swanson. 2009. Before, now, and after: Assessing Hurricane Katrina relief. Population Research and Policy Review 28(1): 31-44.

Fujii, K. 2012. The Great East Japan Earthquake and disabled persons: Background to their high mortality rate. Disability information resources. http://www.dinf.ne.jp/doc/english/twg/ escap_121031/fujii.html. Accessed 15 Feb 2014.

Gowan, M., R. Kirk, and J. Sloan. 2014. Building resiliency: A crosssectional study examining relationships among health-related quality of life, well-being, and disaster preparedness. Health and Quality of Life Outcomes 12(1): 1-40.

Heagele, T. 2016. Lack of evidence supporting the effectiveness of disaster supply kits. American Journal of Public Health 106(6): 979-982.

Heller, K., D. Alexander, M. Gatz, B. Knight, and T. Rose. 2005. Social and personal factors as predictors of earthquake preparation: The role of support provision, network discussion, negative affect, age, and education. Journal of Applied Social Psychology 35(2): 399-422.

Horney, J., C. Snider, S. Malone, L. Gammons, and S. Ramsey. 2008. Factors associated with hurricane preparedness: Results of a prehurricane assessment. Journal of Disaster Research 3(2): 143-149.

Jensen, J. 2014. Emergency Management (EMGT) 761: Preparedness theory and practice: Individual and household preparedness notes.

Jua, N. 1995. Indirect rule in colonial and post-colonial Cameroon. Paideuma 41: 39-47.

Kaniasty, K., and F. Norris. 1995. In search of altruistic community: Patterns of social support mobilization following Hurricane Hugo. American Journal of Community Psychology 23(4): 447-477.

Kano, M., M. Wood, L. Bourque, and D. Mileti. 2011. Terrorism preparedness and exposure reduction since 9/11: The status of public readiness in the United States. Journal of Homeland Security and Emergency Management 8(1): 1-17.

Kapucu, N. 2008. Culture of preparedness: Household disaster preparedness. Disaster Prevention and Management 17(4): $526-535$.

Kelley, M. 2011. Disaster kit contents: A comparison of published guidelines for household preparedness supplies. International Journal of Mass Emergencies and Disasters 34(2): 470-488.

Kim, Y., and J. Kang. 2010. Communication, neighborhood belonging and household hurricane preparedness. Disasters 34(2): $470-488$

Kirschenbaum, A. 1992. Warning and evacuation during a mass disaster: A multivariate decision-making model. International Journal of Mass Emergencies and Disasters 10(1): 91-114.

Kirschenbaum, A. 2002. Disaster preparedness: A conceptual and empirical reevaluation. International Journal of Mass Emergencies and Disasters 20(1): 5-28.

Kölves, K., K.E. Kölves, and D. De Leo. 2013. Natural disasters and suicidal behaviours: A systematic literature review. Journal of Affective Disorders 146(1): 1-14.
Kometa, S. 2012. Ensuring human safety in the disaster prone coastal town of Limbe, Cameroon. Journal of Geography and Geology 4(2): 156-165.

Kusenbach, M., J. Simms, and G. Tobin. 2010. Disaster vulnerability and evacuation readiness: Coastal mobile home residents in Florida. Natural Hazards 52(1): 79-95.

Levac, J., D. Toal-Sullivan, and T. O‘Sullivan. 2012. Household emergency preparedness: A literature review. Journal of Community Health 37(3): 725-733.

Lin, C., L. Siebeneck, M. Lindell, C. Prater, H. Wu, and S. Huang. 2014. Evacuees' information sources and reentry decision making in the aftermath of Hurricane Ike. Natural Hazards 70(1): 865-882.

Lindell, M., and R. Perry. 2000. Household adjustment to earthquake hazard: A review of research. Environment and Behavior 32(4): 461-501.

Lindell, M., and R. Perry. 2012. The protective action decision model: Theoretical modifications and additional evidence. Risk Analysis 32(4): 616-632.

Lindell, M., D. Sutter, and J. Trainor. 2013. Individual and household response to tornadoes. International Journal of Mass Emergencies and Disasters 31(3): 373-383.

Longstaff, P. 2005. Security, resilience, and communication in unpredictable environments such as terrorism, natural disasters, and complex technology. Cambridge, MA: Harvard University and the Center for Information Policy Research.

Maxim, P. 1999. Quantitative research methods in the social sciences. New York: Oxford University Press.

Mileti, D., and J.H. Sorensen. 1990. Communication of emergency public warnings: A social science perspective and state-of-the-art assessment. Washington, DC: U.S. Department of Energy, Office of Scientific and Technical Information. https://www.osti.gov/ biblio/6137387-communication-emergency-public-warningssocial-science-perspective-state-art-assessment. Accessed 15 Feb 2014.

Mileti, D. 1999. Disasters by design: A reassessment of natural hazards in the United States. Washington, DC: Joseph Henry Press.

National Research Council. 2006. Facing hazards and disasters: Understanding human dimensions. Washington, DC: National Academies Press.

Ndille, R., and J. Belle. 2014. Managing the Limbe floods: Considerations for disaster risk reduction in Cameroon. International Journal of Disaster Risk Science 5(2): 147-156.

Nguyen, L., H. Shen, D. Ershoff, A. Afifi, and L. Bourque. 2006. Exploring the causal relationship between exposure to the 1994 Northridge earthquake and pre- and post-earthquake preparedness activities. Earthquake Spectra 22(3): 569-587.

Njome, M., C. Suh, G. Chuyong, and M. de Wit. 2010. Volcanic risk perception in rural communities along the slopes of Mount Cameroon, west-central Africa. Journal of African Earth Sciences 58(4): 608-622.

Norris, F., M. Friedman, P. Watson, C. Byrne, E. Diaz, and K. Kaniasty. 2002. 60,000 disaster victims speak: Part I. An empirical review of the empirical literature, 1981-2001. Psychiatry: Interpersonal and Biological Processes 65(3): 207-239.

Onstad, P., S. Danes, A. Hardman, P. Olson, M. Marczak, R. Heins. 2012. The road to recovery from a natural disaster: Voices from the community. Community Development 43(5): 566-580.

Opdyke, A., A. Javernick-Will, and M. Koschmann. 2018. Household construction knowledge acquisition in post-disaster shelter training. International Journal of Disaster Risk Reduction 28: 131-139.

Patton, M. 2002. Qualitative research and evaluation methods, 3rd edn. Thousand Oaks, CA: Sage. 
Paton, D. 2003. Disaster preparedness: A social-cognitive perspective. Disaster Prevention and Management 12(3): 210-216.

Perman, J., K. Shoaf, A. Kourouyan, and M. Kelley. 2011. Disaster kit contents: A comparison of published guidelines for household preparedness supplies. International Journal of Mass Emergencies and Disasters 29(1): 1-25.

Phibbs, S., G. Good, C. Severinsen, E. Woodbury, and K. Williamson. 2015. Emergency preparedness and perceptions of vulnerability among disabled people following the Christchurch earthquakes: Applying lessons learnt to the Hyogo framework for Action. Australasian Journal of Disaster and Trauma Studies 19: 37-46.

Phillips, B., W. Metz, and L. Nieves. 2005. Disaster threat: Preparedness and potential response of the lowest income quartile. Environmental Hazards 6(3): 123-133.

Pleissis, R., J. Sutherland, L. Gordon, and H. Gibson. 2015. 'The confidence to know I can survive': Resilience and recovery in post-quake Christchurch. New Zealand Journal of Social Sciences Online 10(2): 153-165.

Redlener, I., and D. Berman. 2006. National preparedness planning: The historical context and current state of the U.S. public's readiness, 1940-2005. Journal of International Affairs 59(2): $87-103$.

Ritchie, J., and J. Lewis. 2003. Qualitative research practice: A guide for social science students and researchers. London: Sage.

Rivera, J. 2017. Accessing disaster recovery resource information reliance on social capital in the aftermath of Hurricane Sandy. In Responses to disasters and climate change: Understanding vulnerability and fostering resilience, ed. $\mathrm{M}$. Companion, and $\mathrm{M}$. Chaiken, 61-70. New York: CRC Press.
Ronan, K., K. Crellin, and D. Johnston. 2012. Community readiness for a new tsunami warning system: Quasi-experimental and benchmarking evaluation of a school education component. Natural Hazards 61(3): 1411-1425.

Rouveroy van Nieuwaal, E.A.B. van, and R. van Dijk. 1999. African chieftaincy in a new socio-political landscape. Münster: Lit Verlag.

Rubin, H., and I. Rubin. 2012. Qualitative interviewing: The art of hearing data. 3rd edn. Thousand Oaks, CA: Sage.

Siegel, J., K. Shoaf, A. Afifi, and L. Bourque. 2003. Surviving two disasters: Does reaction to the first predict response to the second? Environment and Behavior 35(5): 637-654.

Spittal, M., J. McClure, R. Siegert, and F. Walkey. 2008. Predictors of two types of earthquake preparation: Survival activities and mitigation activities. Environment and Behavior 40(6): 798-817.

Stough, L.M, A. Sharp, A. Resch, C. Decker, and N. Wilker. 2016. Barriers to the long-term recovery of individuals with disabilities following a disaster. Disasters 40(3): 387-410.

Strauss, A., and J. Corbin. 1998. Basics of qualitative research: Techniques and procedures for developing grounded theory, 2nd edn. Thousand Oaks, CA: Sage.

Tierney, K., M. Lindell, and R. Perry. 2001. Facing the unexpected: Disaster preparedness and response in the United States. Washington, DC: Joseph Henry Press.

Tongwa, A.F., Z.T. Isabella, C. Burnley, and B.W. Gaston. 2012. Local governance in disaster risk reduction in Cameroon. Jàmbá: Journal of Disaster Risk Studies 4(1): 1-9.

Uscher-Pines, L. 2009. Health effects of relocation following disaster: A systematic review of the literature. Disasters 33(1): 1-22. 